\title{
Aerosolized Antibiotics
}

\author{
Marcos I Restrepo MD MSc, Holly Keyt MD, and Luis F Reyes MD
}

\author{
Introduction \\ Pharmacokinetics of Aerosolized Antibiotics \\ Tobramycin \\ Aztreonam \\ Colistin \\ Ciprofloxacin and Levofloxacin \\ Aerosolized Delivery Systems \\ Clinical Indications for Aerosolized Antibiotics \\ Cystic Fibrosis \\ Non-Cystic Fibrosis Bronchiectasis \\ Ventilator-Associated Pneumonia \\ Aerosolized Antibiotics in Combination With Systemic Antibiotics \\ Adverse Effects of Aerosolized Antibiotics \\ Monitoring Clinical Efficacy of Aerosolized Antibiotics \\ Conclusions
}

\begin{abstract}
Administration of medications via aerosolization is potentially an ideal strategy to treat airway diseases. This delivery method ensures high concentrations of the medication in the targeted tissues, the airways, with generally lower systemic absorption and systemic adverse effects. Aerosolized antibiotics have been tested as treatment for bacterial infections in patients with cystic fibrosis (CF), non-CF bronchiectasis (NCFB), and ventilator-associated pneumonia (VAP). The most successful application of this to date is treatment of infections in patients with CF. It has been hypothesized that similar success would be seen in NCFB and in difficult-to-treat hospital-acquired infections such as VAP. This review summarizes the available evidence supporting the use of aerosolized antibiotics and addresses the specific considerations that clinicians should recognize when prescribing an aerosolized antibiotic for patients with CF, NCFB, and VAP. Key words: aerosols; antibacterial agents; cystic fibrosis (CF); bronchiectasis; ventilator-associated pneumonia (VAP). [Respir Care 2015;60(6):762-773. (C) 2015 Daedalus Enterprises]
\end{abstract}

\section{Introduction}

The delivery of medications to the lungs via inhalation or aerosolization has long been recognized as a technique

The authors are affiliated with the University of Texas Health Science Center at San Antonio, San Antonio, Texas. Dr Restrepo is also affiliated with the South Texas Veterans Health Care System, San Antonio, Texas. Dr Reyes is also affiliated with the Universidad de La Sabana, Bogota, Colombia.

Dr Restrepo presented a version of this paper at the 53rd RESPIRATORY CARE Journal Conference, "Aerosol Drug Delivery in Respiratory Care," held June 6-7, 2014, in St Petersburg, Florida. to ensure high local drug concentration with minimal systemic side effects. This mode of therapy is used successfully to deliver bronchodilators and steroids to patients

\footnotetext{
Dr Restrepo was partially supported by National Institutes of Health Grant K23HL096054 from the National Heart, Lung, and Blood Institute. The content is solely the responsibility of the authors and does not necessarily represent the official views of the National Heart, Lung, and Blood Institute or the National Institutes of Health. The funding agencies had no role in the preparation, review, or approval of the manuscript. The views expressed in this article are those of the authors and do not necessarily represent the views of the Department of Veterans Affairs.
} 
with asthma and COPD and is potentially a compelling strategy to target antimicrobial therapy in the treatment of lower respiratory tract infections. The most successful application of this strategy to date is in the treatment of infections in patients with cystic fibrosis (CF). It has been hypothesized that similar efficacy would be seen in patients with non-CF bronchiectasis (NCFB) and in difficultto-treat hospital-acquired infections such as ventilator-associated pneumonia (VAP). This review summarizes the most relevant evidence regarding the use of aerosolized antibiotics in patients with $\mathrm{CF}, \mathrm{NCFB}$, and VAP.

\section{Pharmacokinetics of Aerosolized Antibiotics}

The characteristics that make a medication suitable for aerosolization have been extensively studied. ${ }^{1,2}$ To ensure effective delivery of the medication and to achieve the desired clinical effect with a limited side effect profile, these medications must have relatively physiologic $\mathrm{pH} .^{3}$ They must also penetrate infected airway secretions, not be inactivated by the presence of other medications, and not provoke intolerable adverse effects such as cough, bronchospasm, and hemoptysis. Aminoglycosides, polymyxins, glycopeptides, $\beta$-lactams, monobactams, and fluoroquinolones have been evaluated for delivery via aerosolization with variable results (Table 1).

Antibiotics with concentration-dependent effects (ie, greater area under the curve/minimum inhibitory concentration ratio) are typically chosen for aerosolization, as it is possible to achieve high concentrations in the airway to maximize bacterial killing. Different from time-dependent antibiotics (time over minimum inhibitory concentration of $90 \%$ ), concentration-dependent antibiotics do not need to be present in the target tissue for a long period of time, usually requiring frequent administration. ${ }^{2}$ We review the pharmacokinetics of most commonly used aerosolized antimicrobials, including tobramycin, aztreonam, colistin, levofloxacin, and ciprofloxacin. Unfortunately, measurement of sputum concentrations is not an ideal method for monitoring therapeutic delivery of these medications, as it is not predictive of delivery to the distal airway, which is often the major site of infection. ${ }^{4}$ Therefore, these correlations should be interpreted with caution, and studies showing efficacy with regard to clinically relevant end points should be used to guide clinical decision making.

Correspondence: Marcos I Restrepo MD MSc, 11C6, South Texas Veterans Health Care System ALMD, 7400 Merton Minter Boulevard, San Antonio, TX 78229. E-mail: restrepom@uthscsa.edu.

DOI: $10.4187 /$ respcare. 04208
Table 1. List of the Available and Tested Aerosolized Antibiotics Reported in the Literature for Treatment of Infections Associated With Specific Clinical Conditions

\begin{tabular}{lccc}
\hline \hline \multicolumn{1}{c}{ Antibiotic } & CF & NCFB & VAP \\
\hline Aminoglycosides & & & \\
Gentamicin & Yes & Yes & Yes \\
Colomycin & Yes & Yes & \\
Amikacin & Yes & Yes & Yes \\
Liposomal amikacin & Yes & & \\
Neomycin & Yes & & Yes \\
Sisomycin & Yes & & Yes \\
Tobramycin & Yes & Yes & Yes \\
Polymyxins & & & \\
Colistin/polymyxin B & Yes & Yes & Yes \\
Glycopeptides & & & \\
Vancomycin & & & Yes \\
Monobactams & & & \\
Aztreonam lysine & Yes & & \\
$\beta$-Lactams & & & \\
Ceftazidime & Yes & & \\
Ticarcillin & Yes & & \\
Fluoroquinolones & & & \\
Ciprofloxacin & Yes & & \\
\hline CF = cystic fibrosis & & & \\
NCFB = non-CF bronchiectasis & & & \\
VAP = ventilator-associated pneumonia & & & \\
\hline
\end{tabular}

\section{Tobramycin}

Tobramycin is a bactericidal aminoglycoside antibiotic with activity against Gram-negative organisms. Aminoglycosides act by binding to the $30 \mathrm{~S}$ ribosomal subunit and causing disruption of peptide synthesis. ${ }^{5}$ In general, aminoglycoside antibiotics are chemically stable, have low background levels of resistance, and exert long post-antibiotic effect. ${ }^{6}$ Tobramycin has particular additional advantages: it is available in a generic form, levels can be measured with sensitive assays, and it has an acceptable taste profile. Like other aminoglycosides, tobramycin does not penetrate the lungs and is not ideal for systemic treatment, unless there are no other alternatives or there is a high risk of antimicrobial resistance. ${ }^{2}$ For these reasons, inhaled tobramycin was first investigated for use in children with $\mathrm{CF}$ in the 1980s. ${ }^{7}$ Aerosolized tobramycin was shown to be effective in the treatment of chronic Pseudomonas infection in subjects with CF. ${ }^{6}$ In the 1990 s, a preservative-free, $\mathrm{pH}$-adjusted formulation of tobramycin solution for inhalation was introduced to the market. Nebulization of tobramycin solution for inhalation results in peak sputum levels $\sim 30$ min after administration with minimal, although somewhat variable, systemic absorption. Levels decrease to below the in vitro minimum inhibitory concentration at $\sim 6 \mathrm{~h}$, but exert a particularly long post-antibiotic effect as 
described by Le Brun et $\mathrm{al}^{8}$ in 1999 . The more recently introduced tobramycin dry powder for inhalation has similar pharmacokinetics. ${ }^{9}$ Based on its pharmacokinetics, characteristics, and the available evidence, aerosolized tobramycin (especially in bronchiectasis) appears to be a good treatment alternative. ${ }^{10}$ Aminoglycoside-induced renal failure has been reported in subjects with $\mathrm{CF}$ receiving aerosolized tobramycin solution for inhalation alone, suggesting that some subjects will have greater systemic absorption with a risk of kidney injury. ${ }^{11}$

\section{Aztreonam}

Aztreonam is a synthetic bactericidal monobactam with activity against Gram-negative bacteria, including Pseudomonas aeruginosa. It acts through inhibition of cell wall synthesis and displays typical $\beta$-lactam pharmacokinetics, including a short half-life and slow penetration into bronchial secretions. ${ }^{12}$ Aztreonam solution for inhalation (Cayston, Gilead Sciences, Foster City, California) has an elimination half-life of $\sim 2 \mathrm{~h}$. Approximately $10 \%$ of the delivered dose is ultimately excreted in the urine, and the remainder is thought to be expectorated from the airways.

\section{Colistin}

Colistin is a bactericidal polymyxin antibiotic produced by strains of Bacillus polymyxa subspecies colistinus and acts via disruption of the cell membrane of Gram-negative rods, including P. aeruginosa. Colistin was first discovered in 1949 and introduced into clinical practice in the 1950s. However, it was largely abandoned in the 1980s due to adverse effects, including nephrotoxicity. ${ }^{13}$ More recently, the need to treat patients with highly resistant $P$. aeruginosa lung infections has led to reconsideration of its use as an aerosol. It is used far more commonly in Europe than in North America, in part due to a large difference in medication costs, with the cost in Europe being significantly less (Table 2). ${ }^{14}$

\section{Ciprofloxacin and Levofloxacin}

Fluoroquinolones exert their antibacterial effect through interference with deoxyribonucleic acid (DNA) synthesis. These antibiotics have activity against Gram-negative bacteria, including $P$. aeruginosa, as well as some Gram-positive bacteria, although they do not have reliable activity against methicillin-resistant Staphylococcus aureus (MRSA). In general, fluoroquinolones are characterized by significant tissue penetration. To date, levofloxacin and ciprofloxacin have been evaluated for delivery via aerosolization in patients with $\mathrm{CF}, \mathrm{NCFB}$, and/or VAP.

Aerosolized levofloxacin has been shown to have favorable safety and efficacy profiles in phase- 3 clinical
Table 2. Treatment Outcomes Suggested to Assess the Efficacy of Aerosolized Antibiotics for Treatment of Bacterial Infections in Patients With CF, NCFB, and VAP

\begin{tabular}{lccc}
\hline \multicolumn{1}{c}{ Outcome } & CF & NCFB & VAP \\
\hline $\begin{array}{l}\text { Survival } \\
\text { Prophylactic }\end{array}$ & & Yes \\
Bacterial eradication & & Yes \\
Clinical improvement* & & Yes \\
Reduce exacerbations & & Yes \\
Improve quality of life & Yes & Yes & \\
$\begin{array}{l}\text { Decrease sputum bacterial load } \\
\text { Decrease local inflammation }\end{array}$ & Yes & Yes & \\
& Yes & Yes & \\
* Some studies used Clinical Pulmonary Infection Scores. & & \\
CF $=$ cystic fibrosis & & \\
NCFB $=$ non-CF bronchiectasis & & \\
VAP $=$ ventilator-associated pneumonia & & \\
& & \\
\hline
\end{tabular}

trials. ${ }^{15}$ Earlier phase-1 and phase-2 studies showed that levofloxacin achieved high airway concentrations with little systemic distribution. ${ }^{16}$ Similarly, aerosolized ciprofloxacin achieved high sputum concentrations with a prolonged half-life in phase-1 trials. ${ }^{17}$

\section{Aerosolized Delivery Systems}

To optimize delivery of aerosol medications to the airway, systems are designed with consideration of a number of factors that affect the respirable dose delivered to the patient. ${ }^{18}$ Among these factors are the aerodynamic size of droplets produced (expressed as mass median aerodynamic diameter [MMAD]), the size distribution of the aerosol particles (geometric standard deviation), and the output of the nebulizer. Ideal droplet size ranges from 1- to 5- $\mu \mathrm{m}$ MMAD for airway deposition and $<2-\mu \mathrm{m}$ MMAD for parenchymal deposition. Larger droplets ( $>5-\mu \mathrm{m}$ MMAD) are less likely to reach distal airways and can become trapped in the ventilator circuit or endotracheal tube in mechanically ventilated patients. ${ }^{3}$ The problem with this is not only the resulting failure to eradicate and/or suppress bacterial load, but also the possibility of an increase in antimicrobial resistance.

Ilowite et al ${ }^{19}$ reported the complexity of this issue by considering the interaction of the type of nebulizer, droplet size, and the dose of aerosolized antibiotics to the lung. The authors showed that aerosolized gentamicin deposited on average $8 \%$ of the original amount placed in the nebulizer. They also confirmed high peak sputum concentration of gentamicin and undetectable serum levels.

For spontaneously breathing patients with $\mathrm{CF}$ and NCFB, nebulizer systems have been developed and marketed for use with specific antibiotics. Examples of this include Cayston, which is administered using the Altera vibrating mesh nebulizer system (PARI Respiratory Equipment, Midlothian, Virginia), and tobramycin solution for inhalation (mar- 
keted as TOBI, Novartis, New York, New York), which is administered using only specifically studied and approved nebulizers. In general, these nebulizer systems are portable and able to deliver the medications with minimal waste. Cayston administration requires 2-3 min for treatment and is given 3 times daily. TOBI administration requires $10-15 \mathrm{~min}$ for nebulization and is given twice daily. To lessen this burden of treatment, dry powder tobramycin for inhalation has been developed, which decreases treatment time to 2-3 min. Other antibiotics have been administered via investigational nebulizers not currently available on the market. ${ }^{16}$

Ideal methods for delivery of nebulized medications to mechanically ventilated patients have not been determined. An important factor that affects drug delivery in these patients is the humidity within the ventilator circuits. Delivery failure can result from hydroscopic growth and rainout effect within the tubing. ${ }^{20}$ There are several available delivery systems in use. The AeroTech II (Biodex Medical Systems, Shirley, New York) is a classic jet nebulizer that requires continuous air flow and connection to the ventilator in the inspiratory branch. The AeroTech II can nebulize antibiotics, bypassing the humidification system, and produces particles with an MMAD of $\sim 1.5 \mu \mathrm{m} .{ }^{20}$

The pulmonary drug delivery system from Bayer HealthCare and Nektar Therapeutics (San Francisco, California) is a vibrating mesh nebulizer located distal to the ventilator Y-piece. This single-use system is triggered by a pressure-sensing device and delivers drug during inspiration only. This system is currently in phase-3 trials evaluating the efficacy of inhaled amikacin. ${ }^{21}$ Vibrating mesh nebulizers have been shown to be effective in the delivery of antibiotics to ventilated patients. This is attributed in part to lower residual volume and the location of the medication reservoir separated from the ventilator circuit, reducing the risk of contamination. ${ }^{22}$

The PARI eFlow in-line nebulizer system is a vibrating mesh nebulizer with a stainless-steel vibrating plate placed on the inspiratory arm of the ventilator. This system uses a bias flow to perform continuous nebulization while the humidification system is active. After exposure to humidity, the molecules reach an MMAD of $\sim 3.2 \mu \mathrm{m}$. The median delivery time is $12 \mathrm{~min}$, and it is a multiple-use nebulizer. ${ }^{23}$

\section{Clinical Indications for Aerosolized Antibiotics}

It is hypothesized that aerosolized antibiotics could improve airway inflammation and ultimately lead to improved clinical outcomes based on the principle that antibiotics decrease bacterial density in the airways and therefore decrease inflammation and lung damage. ${ }^{24}$ We discuss the most relevant literature regarding the clinical application of aerosolized antibiotics for patients with $\mathrm{CF}, \mathrm{NCFB}$, and VAP infected with difficult-to-treat pathogens., 10,25-29

\section{Cystic Fibrosis}

Lo et $\mathrm{al}^{28}$ evaluated the effectiveness of treatment regimens designed to eradicate MRSA in CF and to determine whether MRSA eradication was associated with better clinical and microbiological outcomes for subjects with CF. The authors were not able to identify randomized controlled trials (RCTs) that would allow them to make evidence-based recommendations. In contrast, early treatment for $P$. aeruginosa infection in children and adults with $\mathrm{CF}$ delayed onset of chronic infection and resulted in clinical improvement. ${ }^{10}$ The authors found 49 trials, but included only trials that evaluated duration of nebulized antibiotics for between $28 \mathrm{~d}$ and 27 months. The authors concluded that nebulized antibiotics, alone or in combination with oral antibiotics, were better than no treatment for early infection with $P$. aeruginosa. They found insufficient evidence to support that nebulized antibiotics improved morbidity and mortality in subjects with CF.

Tobramycin solution for inhalation is the best-studied aerosolized antibiotic for use in patients with $\mathrm{CF}$ and chronic $P$. aeruginosa infection. In RCTs, the use of tobramycin solution for inhalation was associated with improved pulmonary function, decreased exacerbation frequency, decreased density of $P$. aeruginosa in sputum, improved quality of life, and decreased hospitalization rates. ${ }^{27,30,31}$ Long-term follow-up trials have confirmed improvement in lung function in these subjects as long as treatment is continued. ${ }^{32}$

The American Thoracic Society (ATS) assigned a grade-A recommendation to the use of tobramycin solution for inhalation for patients $\geq 6 \mathrm{y}$ of age with moderateto-severe lung disease and persistent $P$. aeruginosa growth from airway cultures. ${ }^{33}$ This recommendation was based on pooled data including 1,110 subjects from 6 RCTs and one randomized crossover trial. In subjects with mild disease who are $\geq 6$ y old, inhaled tobramycin was given a grade-B recommendation to reduce exacerbations based on 3 RCTs enrolling 234 subjects. ${ }^{34-36}$

The outcomes of tobramycin dry powder for inhalation use in patients with CF are less well studied. The EAGER trial $^{6}$ was a large (533 subjects), international, open-label, non-inferiority RCT that compared tobramycin dry powder and solution for inhalation, with a primary end point of clinically important change in $\mathrm{FEV}_{1}$. At 24 weeks (3 cycles of $28 \mathrm{~d}$ on/28 d off), tobramycin dry powder for inhalation was found to be non-inferior to tobramycin solution for inhalation. However, a significant number of participants dropped out from the intervention arm due to adverse events (particularly cough), and there was no clear evidence regarding the effect of tobramycin dry powder for inhalation on exacerbation frequency. ${ }^{27}$ Therefore, the non-inferiority of dry powder for inhalation treatments compared with nebulized tobramycin remains unclear. 
Similar to tobramycin solution for inhalation, aztreonam solution for inhalation has significantly improved clinical outcomes in patients with CF compared with placebo. McCoy et $\mathrm{al}^{37}$ showed that $\mathrm{CF}$ subjects treated with inhaled aztreonam twice daily had a prolonged time to exacerbation compared with placebo (92 vs $71 \mathrm{~d}, P=.002$ ) and a significant absolute improvement in $\mathrm{FEV}_{1}$ as well as improvement in quality of life. Retsch-Bogart et $\mathrm{al}^{38}$ demonstrated a decrease in hospital days for CF subjects with moderate-to-severe lung disease treated with inhaled aztreonam compared with placebo ( 0.5 vs $1.5 \mathrm{~d}, P=.049)$ as well as a similar improvement in $\mathrm{FEV}_{1}$ as in the McCoy study. ${ }^{37}$ An 18-month open-label investigation suggested that long-term use of inhaled aztreonam every other month is safe and effective ${ }^{39}$ and not associated with resistance to aztreonam. ${ }^{40}$ For these reasons, the ATS guidelines for management of chronic CF-related pulmonary disease assigned a grade-A recommendation for use of inhaled aztreonam in patients $\geq 6$ y of age with moderate-to-severe lung disease and persistently positive cultures for $P$. aeruginosa.

To date, there is one well-designed study of inhaled aztreonam in subjects with mild CF-related lung disease ( $\mathrm{FEV}_{1}$ of $>75 \%$ of predicted); this study showed a relative improvement in $\mathrm{FEV}_{1}$ compared with placebo and a modest improvement in quality of life. ${ }^{41}$ Therefore, the ATS committee gave the use of inhaled aztreonam in patients with mild disease a grade-B recommendation.

There are insufficient data for other inhaled antibiotics, including fluoroquinolones, colistin, and gentamicin, to carry a recommendation from the ATS for chronic use in patients with CF. We support the Cystic Fibrosis Foundation clinical practice guidelines ${ }^{33}$ regarding the prevention and eradication of initial P. aeruginosa infection; these guidelines recommend inhaled antibiotic therapy for the treatment of initial or new growth of $P$. aeruginosa from an airway culture. The favored antibiotic regimen was tobramycin solution for inhalation at $300 \mathrm{mg}$ twice daily for $28 \mathrm{~d}$. However, they recommended against the use of prophylactic antibiotics to prevent the acquisition of $P$. aeruginosa.

\section{Non-Cystic Fibrosis Bronchiectasis}

Chalmers et $\mathrm{al}^{24}$ showed a direct correlation between airway bacterial load, airway and systemic inflammation, and greater risk of exacerbations. They demonstrated that shortterm (14 d) and long-term (up to 12 months) antibiotic therapy reduced markers of airway and systemic inflammation. The authors concluded that monitoring sputum bacteriology when clinically stable is important and provides evidence for future interventions with the objective of reducing the bacterial burden in the airways. ${ }^{24}$ Based on the efficacy seen in patients with CF, aerosolized aminoglycosides, aztreonam, and colistin have been investigated for use in patients with NCFB. Several studies with inhaled tobramycin have shown a reduction in Pseudomonas bacterial load. ${ }^{42-46}$ In addition, studies reported lower exacerba- tion or hospitalization rates in subjects receiving inhaled tobramycin. ${ }^{44-46}$ In a study by Dhar et $\mathrm{al},{ }^{43}$ nebulized colomycin appeared to reduce exacerbation frequency, hospitalization, and sputum volume in $P$. aeruginosa-colonized subjects with NCFB. Murray et $\mathrm{al}^{47}$ reported an RCT of twice-daily nebulized gentamicin compared with placebo that showed long-term nebulized gentamicin was associated with reduced $P$. aeruginos $a$ and other bacterial density, less sputum purulence, and greater exercise capacity. In addition, nebulized gentamicin was also associated with fewer exacerbations, increased time to first exacerbation, and improved quality of life.

In contrast to the positive results observed in $\mathrm{CF}$, the use of aztreonam was not associated with clinical benefit in subjects with NCFB. ${ }^{48}$ An ongoing study of dry powder ciprofloxacin inhalation is likely to have results in the near future. In a phase-2 Australian/New Zealand multi-center double-blind placebo-controlled randomized trial in 42 subjects with NCFB, Serisier et $\mathrm{al}^{49}$ demonstrated potent antipseudomonal microbiological efficacy using dual-release ciprofloxacin for inhalation containing liposomal ciprofloxacin. The medication was well tolerated and delayed time to first pulmonary exacerbation.

Eradication of bacteria is a complex issue in patients with NCFB. White et al $^{50}$ reported a retrospective study of subjects with $P$. aeruginosa NCFB. Subjects were managed with nebulized colistin for a 3-month period in addition to intravenous antibiotics, followed by oral ciprofloxacin. These regimens showed $80 \%$ P. aeruginosa eradication in expectorated sputum, leading to prolonged clearance and reduced exacerbation rates. However, it is unclear how much of this effect was attributed to the use of nebulized colistin.

The British Thoracic Society guidelines for management of patients with NCFB recommend aerosolized antibiotics for patients who are chronically colonized with $P$. aeruginosa and experience frequent exacerbations $(\geq 3 / y)$ or fewer exacerbations that cause significant morbidity. ${ }^{51} \mathrm{~A}$ recent meta-analysis by $\mathrm{Yang}$ et $\mathrm{al}^{4}$ identified 8 RCTs recruiting 539 subjects with NCFB. The authors showed that long-term use of inhaled antibiotics was associated with reduction in sputum bacterial density, and increased $P$. aeruginos $a$ eradication, and attenuation of exacerbation risk. However, the use of long-term inhaled antibiotics was associated with a higher risk of wheeze (odds ratio of 6.7) and bronchospasm (odds ratio of 2.8). Similar results were previously reported by Brodt et al, ${ }^{26}$ suggesting that inhaled antibiotics may provide an effective suppressive antibiotic therapy. However, in contrast, they concluded that inhaled antibiotics have an acceptable profile for adult subjects with NCFB and chronic bronchial infection. Therefore, we believe that there is a growing body of literature supporting the use of aerosolized antibiotics in the treatment of NCFB patients infected with $P$. aeruginosa, but important attention should be placed to bronchospasm in this group of patients. 


\section{Ventilator-Associated Pneumonia}

Although the use of aerosolized antibiotics is considered to be standard of care in the management of chronic CF-related pulmonary disease and is recommended for some patients with NCFB, there is no clear consensus about the use of aerosolized antibiotics in patients with VAP. Aerosolized antibiotics are reserved mainly for adjunctive therapy in these patients with multidrug-resistant (MDR) pathogens. ${ }^{52}$

VAP is the leading cause of death related to infection in mechanically ventilated patients. ${ }^{53}$ MDR pathogens such as $P$. aeruginosa, Acinetobacter subspecies, and $S$. aureus represent the most important group of pathogens causing VAP. ${ }^{54}$ In pneumonia, adjunctive therapies with aerosolized antibiotics are recommended only for difficult-to-treat MDR pathogens, especially in cases of clinical failure. ${ }^{52}$ The antibiotics most commonly used in clinical practice for patients with VAP include aminoglycosides and colistin/polymyxin B. ${ }^{55}$ A combination of tobramycin instilled locally and intravenous therapy showed no improvement in clinical outcomes but better microbiological eradication in VAP subjects receiving aerosolized antibiotics. ${ }^{56}$ Rescue therapy is used for treatment of MDR P. aeruginosa infections unresponsive to systemic antibiotics.

The major concerns about the use of aerosolized antibiotics in patients with VAP include adverse effects such as bronchospasm and development of further resistant pathogens, particularly when used as prophylactic agents rather than as treatment for acute infection. ${ }^{57}$ In a metaanalysis of RCTs, Falagas et al $^{13}$ reported that aerosolized antibiotics reduced the rate of VAP but had no effect on mortality and concluded that there is insufficient evidence to assess the effect on bacterial colonization. However, this analysis included older prophylactic studies with different delivery systems and different rates of baseline incidence of MDR pathogens, which may not represent the current epidemiology and ecology of patients with VAP. Limited data are available regarding the use of aerosolized antibiotics in treating patients with VAP or ventilator-associated tracheobronchitis. In a meta-analysis of 176 subjects with nosocomial infection in $5 \mathrm{RCTs}$, Ioannidou et al ${ }^{58}$ reported that aerosolized antibiotics had no effect on mortality, microbiological eradication, and rate of adverse effects. Therefore, it is recommended that aerosolized antibiotics be considered as adjunctive therapy in subjects infected with MDR Gram-negative bacteria failing systemic antibiotics. ${ }^{59}$

\section{Aerosolized Antibiotics in Combination With Systemic Antibiotics}

Limited data are available regarding the concomitant use of systemic and aerosolized antibiotics. In patients with VAP, the use of concomitant treatment with systemic and aerosolized antibiotics is reserved for those patients infected with MDR pathogens. Recently, Valachis et al ${ }^{14}$ published a systematic review and meta-analysis of 16 studies and concluded that concomitant treatment with colistin was associated with improved outcomes in the treatment of VAP, but the quality of the evidence was low. With the evidence that is available today, the recommendation for concomitant treatment should remain for patients with MDR pathogens and in cases in which systemic antibiotics were not effective. ${ }^{60-64}$

\section{Adverse Effects of Aerosolized Antibiotics}

The most common adverse effects reported with administration of aerosolized antibiotics include cough, wheezing, hemoptysis, and dyspnea with considerable variation by antibiotic (Table 3). The preparation of inhaled tobramycin that was initially studied included a preservative that was irritating to the airway. The currently used, FDAapproved, preservative-free preparation of tobramycin solution for inhalation may cause less bronchospasm. ${ }^{65,66}$ Pretreatment with bronchodilators appears to mitigate this problem in patients with $\mathrm{CF}$.

Other significantly cited adverse events associated with tobramycin solution for inhalation are voice alteration and tinnitus. In the pivotal trials investigating the safety and efficacy of tobramycin solution for inhalation in subjects with $\mathrm{CF}$, voice alteration was usually mild to moderate in severity, improved during off-drug cycles, and decreased steadily in incidence with increasing tobramycin solution for inhalation exposure (from 9.1 to 3.9\%). Tinnitus was rare among subjects treated with tobramycin solution for inhalation, never exceeding a frequency of 3.5\%. Most episodes were transient and mild or moderate in severity. Audiology testing showed no evidence of objective hearing loss. ${ }^{67}$ There have also been cases reported in the literature of acute renal failure, ${ }^{11}$ hearing loss, ${ }^{68}$ and vestibular toxicity. ${ }^{69}$

Unfortunately, patients with severe NCFB seem to have worse adverse events associated with tobramycin solution for inhalation compared with patients with CF. In a pilot study to evaluate the safety and efficacy of tobramycin solution for inhalation in subjects with severe NCFB, 10 of 41 enrolled subjects withdrew from the study due to adverse events, most commonly cough, wheezing, and dyspnea. ${ }^{46}$

Inhaled aztreonam is well tolerated by patients with CF. The most commonly reported adverse reaction is cough, which occurs in $15 \%$ of patients treated with inhaled aztreonam compared with $10 \%$ of patients treated with placebo. In phase-3 studies, subject discontinuation due to adverse effects was actually higher in the placebo-treated 
Table 3. Adverse Effects Associated With the Use of Aerosolized Antibiotics in Different Groups of Patients With Cystic Fibrosis, Non-Cystic Fibrosis Bronchiectasis, and Ventilator-Associated Pneumonia

\begin{tabular}{|c|c|c|c|c|c|c|c|}
\hline \multirow{3}{*}{ Adverse Effect } & \multicolumn{7}{|c|}{ Frequency Per Antibiotic (\%) } \\
\hline & \multicolumn{3}{|c|}{ Aminoglycosides } & \multicolumn{4}{|c|}{ Others } \\
\hline & Gentamicin & Amikacin & Tobramycin & Colistin & Vancomycin & Aztreonam & Ceftazidime \\
\hline Nephrotoxicity & NR & $<10$ & $<10$ & $<10$ & $<10$ & NR & NR \\
\hline Neurotoxicity & NR & NR & $<10$ & NR & NR & NR & NR \\
\hline Wheezing & $<10$ & $<10$ & $11-20^{*}$ & NR & NR & $11-20$ & $<10$ \\
\hline Cough & $<10$ & $<10$ & $11-20 *$ & NR & NR & $21-40$ & $<10$ \\
\hline Bronchospasm & $21-40$ & $<10$ & $11-20^{*}$ & NR & $<10$ & $<10$ & NR \\
\hline Hypersensitivity pneumonitis & NR & $<10$ & $11-20$ & $<10$ & NR & $<10$ & NR \\
\hline Hemoptysis & NR & NR & $11-20$ & NR & NR & $21-40$ & NR \\
\hline Others & $<10$ & $<10$ & $<10$ & $<10$ & $<10$ & $<10$ & $<10$ \\
\hline
\end{tabular}

group $(16 \%)$ than in the inhaled aztreonam-treated group $(7 \%) .{ }^{12,37-39}$

The development of resistant strains of bacteria is also a concern with chronic antibiotic use. However, this has been shown to be time-dependent and decreases with time after discontinuation of the antibiotic. ${ }^{70,71}$

\section{Monitoring Clinical Efficacy of Aerosolized Antibiotics}

How to monitor the effectiveness of aerosolized antibiotic treatment is not clear, but in general, the clinical response rate (ie, complete or partial resolution of the signs and symptoms of infection by the end of therapy) is frequently used to determine its effectiveness. ${ }^{14}$ Additionally, some researchers have shown that microbiological eradication (ie, no growth of the causative/colonization pathogen at the end of therapy) might be useful, especially in subjects with CF. Outcomes most frequently used in studies to evaluate the effectiveness of an aerosolized antibiotic are listed in Table 2.

VAP is a complex disease with a wide range of presentations, but in general, patients with VAP are severely ill, and it therefore follows that clinical outcomes are more important than microbiological eradication. ${ }^{14}$ Some studies have shown that microbiological eradication in sputum or bronchoalveolar lavage may be an effective way to monitor the effectiveness of VAP treatment. ${ }^{47,63,72}$ Other studies have used a pneumonia severity index such as the Clinical Pulmonary Infection Score to assess clinical improvement with non-conclusive results. ${ }^{62}$

In contrast, patients with bronchiectasis (with or without $\mathrm{CF}$ ) could be chronically colonized with MDR pathogens, leading to chronic inflammation with multiple complications. ${ }^{47}$ As a result, treatment strategies for aerosolized antibiotics in patients with $\mathrm{CF}$ and NCFB are usually not curative but rather more suppressive of bacterial burden. The treatment effectiveness of aerosolized antibiotics in patients with bronchiectasis can also be evaluated by measuring the inflammatory response (in sputum or systemically). The adequate control of chronic inflammation has been associated with improvement in clinical outcomes. ${ }^{24}$

\section{Conclusions}

The potential of aerosolized antibiotics to deliver high concentrations of effective drug directly to the site of infection while minimizing systemic effects is appealing. In patients with $\mathrm{CF}$ and chronic $P$. aeruginosa infection, aerosolized antibiotics are delivered via portable nebulizer systems and have shown significant impacts on clinical outcomes. For the majority of patients with $\mathrm{CF}$, these medications are part of a therapeutic regimen that has increased median survival to $>40 \mathrm{y}$. Further advances in delivery systems and investigation into the efficacy of more antibiotics are ongoing.

For patients with NCFB, aerosolized antibiotics may also decrease morbidity. Long-term RCTs of available antibiotics and delivery systems are needed to further inform the clinician about regular use of these medications, but for now, aerosolized antibiotics should be considered for patients with frequent exacerbations or with exacerbations causing significant morbidity.

The data supporting use of aerosolized antibiotics in patients with VAP are limited. Ventilator systems interfere with predictable delivery of medications to these patients' airways. However, further technological advances may overcome this challenge and should be pursued. In an era of increasing infections caused by MDR organisms, the promise of more efficacious delivery of appropriate anti- 
biotic therapy with minimal systemic absorption is compelling. We look forward to the bright future of research into aerosolized antibiotics.

\section{REFERENCES}

1. Stockmann C, Roberts JK, Yellepeddi VK, Sherwin CM. Clinical pharmacokinetics of inhaled antimicrobials. Clin Pharmacokinet 2015;54(5):473-492.

2. Hochhaus G, Horhota S, Hendeles L, Suarez S, Rebello J. Pharmacokinetics of orally inhaled drug products. AAPS J 2015;17(3):769775 .

3. Fink J, Ari A. Aerosol delivery to intubated patients. Expert Opin Drug Deliv 2013;10(8):1077-1093.

4. Yang JW, Fan LC, Lu HW, Miao XY, Mao B, Xu JF. Efficacy and safety of long-term inhaled antibiotic for patients with noncystic fibrosis bronchiectasis: a meta-analysis. Clin Respir J 2015 [Epub ahead of print] doi: 10.1111/crj.12278.

5. Konstan MW, Geller DE, Minić P, Brockhaus F, Zhang J, Angyalosi G. Tobramycin inhalation powder for $P$. aeruginosa infection in cystic fibrosis: the EVOLVE trial. Pediatr Pulmonol 2011;46(3):230238.

6. Konstan MW, Flume PA, Kappler M, Chiron R, Higgins M, Brockhaus F, et al. Safety, efficacy and convenience of tobramycin inhalation powder in cystic fibrosis patients: the EAGER trial. J Cyst Fibros 2011;10(1):54-61.

7. Stephens D, Garey N, Isles A, Levison H, Gold R. Efficacy of inhaled tobramycin in the treatment of pulmonary exacerbations in children with cystic fibrosis. Pediatr Infect Dis 1983;2(3):209-211.

8. Le Brun PP, Vinks AA, Touw DJ, Hekelaar N, Mannes GP, Brimicombe RW, et al. Can tobramycin inhalation be improved with a jet nebulizer? Ther Drug Monit 1999;21(6):618-624.

9. Geller DE, Konstan MW, Smith J, Noonberg SB, Conrad C. Novel tobramycin inhalation powder in cystic fibrosis subjects: pharmacokinetics and safety. Pediatr Pulmonol 2007;42(4):307-313.

10. Langton Hewer SC, Smyth AR. Antibiotic strategies for eradicating Pseudomonas aeruginosa in people with cystic fibrosis. Cochrane Database Syst Rev 2009;4:CD004197.

11. Hoffmann IM, Rubin BK, Iskandar SS, Schechter MS, Nagaraj SK, Bitzan MM. Acute renal failure in cystic fibrosis: association with inhaled tobramycin therapy. Pediatr Pulmonol 2002;34(5):375-377.

12. Gibson RL, Retsch-Bogart GZ, Oermann C, Milla C, Pilewski J, Daines C, et al. Microbiology, safety, and pharmacokinetics of aztreonam lysinate for inhalation in patients with cystic fibrosis. Pediatr Pulmonol 2006;41(7):656-665.

13. Falagas ME, Siempos II, Bliziotis IA, Michalopoulos A. Administration of antibiotics via the respiratory tract for the prevention of ICU-acquired pneumonia: a meta-analysis of comparative trials. Crit Care 2006;10(4):R123.

14. Valachis A, Samonis G, Kofteridis DP. The role of aerosolized colistin in the treatment of ventilator-associated pneumonia: a systematic review and metaanalysis. Crit Care Med 2015;43(3):527-533.

15. Stockmann C, Sherwin CM, Ampofo K, Spigarelli MG. Development of levofloxacin inhalation solution to treat Pseudomonas aeruginosa in patients with cystic fibrosis. Ther Adv Respir Dis 2014;8(1): 13-21.

16. Geller DE, Flume PA, Staab D, Fischer R, Loutit JS, Conrad DJ, Mpex 204 Study Group. Levofloxacin inhalation solution (MP-376) in patients with cystic fibrosis with Pseudomonas aeruginosa. Am J Respir Crit Care Med 2011;183(11):1510-1516.

17. Stass H, Weimann B, Nagelschmitz J, Rolinck-Werninghaus C, Staab D. Tolerability and pharmacokinetic properties of ciprofloxacin dry powder for inhalation in patients with cystic fibrosis: a phase I, randomized, dose-escalation study. Clin Ther 2013;35(10):15711581.

18. Kollef MH, Hamilton CW, Montgomery AB. Aerosolized antibiotics: do they add to the treatment of pneumonia? Curr Opin Infect Dis 2013;26(6):538-544.

19. Ilowite JS, Gorvoy JD, Smaldone GC. Quantitative deposition of aerosolized gentamicin in cystic fibrosis. Am Rev Respir Dis 1987; 136(6):1445-1449.

20. Miller DD, Amin MM, Palmer LB, Shah AR, Smaldone GC. Aerosol delivery and modern mechanical ventilation: in vitro/in vivo evaluation. Am J Respir Crit Care Med 2003;168(10):1205-1209.

21. Niederman MS, Chastre J, Corkery K, Fink JB, Luyt CE, García MS. BAY41-6551 achieves bactericidal tracheal aspirate amikacin concentrations in mechanically ventilated patients with Gram-negative pneumonia. Intensive Care Med 2012;38(2):263-271.

22. Ferrari F, Liu ZH, Lu Q, Becquemin MH, Louchahi K, Aymard G, et al. Comparison of lung tissue concentrations of nebulized ceftazidime in ventilated piglets: ultrasonic versus vibrating plate nebulizers. Intensive Care Med 2008;34(9):1718-1723.

23. Montgomery AB, Rhomberg PR, Abuan T, Walters KA, Flamm RK. Potentiation effects of amikacin and fosfomycin against selected amikacin-non-susceptible Gram-negative respiratory tract pathogens. Antimicrob Agents Chemother 2014;58(7):3714-3719.

24. Chalmers JD, Smith MP, McHugh BJ, Doherty C, Govan JR, Hill AT. Short- and long-term antibiotic treatment reduces airway and systemic inflammation in non-cystic fibrosis bronchiectasis. Am J Respir Crit Care Med 2012;186(7):657-665.

25. Zampieri FG, Nassar AP Jr, Gusmao-Flores D, Taniguchi LU, Torres A, Ranzani OT. Nebulized antibiotics for ventilator-associated pneumonia: a systematic review and meta-analysis. Crit Care 2015; 19(1): 150.

26. Brodt AM, Stovold E, Zhang L. Inhaled antibiotics for stable noncystic fibrosis bronchiectasis: a systematic review. Eur Respir J 2014; 44(2):382-393.

27. Uttley L, Harnan S, Cantrell A, Taylor C, Walshaw M, Brownlee K, Tappenden P. Systematic review of the dry powder inhalers colistimethate sodium and tobramycin in cystic fibrosis. Eur Respir Rev 2013;22(130):476-486.

28. Lo DK, Hurley MN, Muhlebach MS, Smyth AR. Interventions for the eradication of methicillin-resistant Staphylococcus aureus (MRSA) in people with cystic fibrosis. Cochrane Database Syst Rev 2013;2:CD009650.

29. Ryan G, Jahnke N, Remmington T. Inhaled antibiotics for pulmonary exacerbations in cystic fibrosis. Cochrane Database Syst Rev 2012;12:CD008319.

30. Falagas ME, Trigkidis KK, Vardakas KZ. Inhaled antibiotics beyond aminoglycosides, polymyxins and aztreonam: a systematic review. Int J Antimicrob Agents 2015;45(3):221-233.

31. Máiz L, Girón RM, Olveira C, Quintana E, Lamas A, Pastor D, et al. Inhaled antibiotics for the treatment of chronic bronchopulmonary Pseudomonas aeruginosa infection in cystic fibrosis: systematic review of randomised controlled trials. Expert Opin Pharmacother 2013; 14(9):1135-1149.

32. Moss RB. Administration of aerosolized antibiotics in cystic fibrosis patients. Chest 2001;120(3 Suppl):107S-113S.

33. Mogayzel PJ Jr, Naureckas ET, Robinson KA, Mueller G, Hadjiliadis D, Hoag JB, et al. Cystic fibrosis pulmonary guidelines. Chronic medications for maintenance of lung health. Am J Respir Crit Care Med 2013;187(7):680-689.

34. Murphy TD, Anbar RD, Lester LA, Nasr SZ, Nickerson B, VanDevanter DR, Colin AA. Treatment with tobramycin solution for inhalation reduces hospitalizations in young $\mathrm{CF}$ subjects with mild lung disease. Pediatr Pulmonol 2004;38(4):314-320. 
35. Nasr SZ, Sakmar E, Christodoulou E, Eckhardt BP, Streetman DS, Strouse PJ. The use of high resolution computerized tomography (HRCT) of the chest in evaluating the effect of tobramycin solution for inhalation in cystic fibrosis lung disease. Pediatr Pulmonol 2010; 45(5):440-449.

36. Gibson RL, Emerson J, McNamara S, Burns JL, Rosenfeld M, Yunker A, et al. Significant microbiological effect of inhaled tobramycin in young children with cystic fibrosis. Am J Respir Crit Care Med 2003;167(6):841-849.

37. McCoy KS, Quittner AL, Oermann CM, Gibson RL, Retsch-Bogart GZ, Montgomery AB. Inhaled aztreonam lysine for chronic airway Pseudomonas aeruginosa in cystic fibrosis. Am J Respir Crit Care Med 2008;178(9):921-928.

38. Retsch-Bogart GZ, Quittner AL, Gibson RL, Oermann CM, McCoy KS, Montgomery AB, Cooper PJ. Efficacy and safety of inhaled aztreonam lysine for airway pseudomonas in cystic fibrosis. Chest 2009;135(5):1223-1232.

39. Oermann CM, Retsch-Bogart GZ, Quittner AL, Gibson RL, McCoy KS, Montgomery AB, Cooper PJ. An 18-month study of the safety and efficacy of repeated courses of inhaled aztreonam lysine in cystic fibrosis. Pediatr Pulmonol 2010;45(11):1121-1134.

40. Oermann CM, McCoy KS, Retsch-Bogart GZ, Gibson RL, McKevitt M, Montgomery AB. Pseudomonas aeruginosa antibiotic susceptibility during long-term use of aztreonam for inhalation solution (AZLI). J Antimicrob Chemother 2011;66(10):2398-2404.

41. Wainwright CE, Quittner AL, Geller DE, Nakamura C, Wooldridge JL, Gibson RL, et al. Aztreonam for inhalation solution (AZLI) in patients with cystic fibrosis, mild lung impairment, and P. aeruginosa. J Cyst Fibros 2011;10(4):234-242.

42. Barker AF, Couch L, Fiel SB, Gotfried MH, Ilowite J, Meyer KC, et al. Tobramycin solution for inhalation reduces sputum Pseudomonas aeruginosa density in bronchiectasis. Am J Respir Crit Care Med 2000;162(2 Pt 1):481-485.

43. Dhar R, Anwar GA, Bourke SC, Doherty L, Middleton P, Ward C, Rutherford RM. Efficacy of nebulised colomycin in patients with non-cystic fibrosis bronchiectasis colonised with Pseudomonas aeruginosa. Thorax 2010;65(6):553.

44. Drobnic ME, Suñé P, Montoro JB, Ferrer A, Orriols R. Inhaled tobramycin in non-cystic fibrosis patients with bronchiectasis and chronic bronchial infection with Pseudomonas aeruginosa. Ann Pharmacother 2005;39(1):39-44.

45. Orriols R, Roig J, Ferrer J, Sampol G, Rosell A, Ferrer A, Vallano A. Inhaled antibiotic therapy in non-cystic fibrosis patients with bronchiectasis and chronic bronchial infection by Pseudomonas aeruginosa. Respir Med 1999;93(7):476-480.

46. Scheinberg P, Shore E. A pilot study of the safety and efficacy of tobramycin solution for inhalation in patients with severe bronchiectasis. Chest 2005;127(4):1420-1426.

47. Murray MP, Govan JR, Doherty CJ, Simpson AJ, Wilkinson TS, Chalmers JD, et al. A randomized controlled trial of nebulized gentamicin in non-cystic fibrosis bronchiectasis. Am J Respir Crit Care Med 2011;183(4):491-499.

48. Barker AF, O'Donnell A, Thompson PJ, Flume PA, Ruzi J, Garcia $\mathrm{J}$, et al. Two phase 3 placebo-controlled trials of aztreonam lysine for inhalation (AZLI) for non-cystic fibrosis bronchiectasis (NCFB). Eur Respir J 2013;42(Suppl 57):P4136.

49. Serisier DJ, Bilton D, De Soyza A, Thompson PJ, Kolbe J, Greville $\mathrm{HW}$, et al. Inhaled, dual release liposomal ciprofloxacin in noncystic fibrosis bronchiectasis (ORBIT-2): a randomised, double-blind, placebo-controlled trial. Thorax 2013;68(9):812-817.

50. White L, Mirrani G, Grover M, Rollason J, Malin A, Suntharalingam J. Outcomes of Pseudomonas eradication therapy in patients with non-cystic fibrosis bronchiectasis. Respir Med 2012; 106(3):356-360.
51. Pasteur MC, Bilton D, Hill AT, British Thoracic Society Bronchiectasis Non-CF Guideline Group. British Thoracic Society guideline for non-CF bronchiectasis. Thorax 2010;65:i1-i58.

52. American Thoracic Society, Infectious Diseases Society of America. Guidelines for the management of adults with hospital-acquired, ventilator-associated, and healthcare-associated pneumonia. Am J Respir Crit Care Med 2005;171(4):388-416.

53. Chastre J, Fagon JY. Ventilator-associated pneumonia. Am J Respir Crit Care Med 2002;165(7):867-903.

54. Barbier F, Andremont A, Wolff M, Bouadma L. Hospital-acquired pneumonia and ventilator-associated pneumonia: recent advances in epidemiology and management. Curr Opin Pulm Med 2013;19(3): 216-228.

55. Hamer DH. Treatment of nosocomial pneumonia and tracheobronchitis caused by multidrug-resistant Pseudomonas aeruginosa with aerosolized colistin. Am J Respir Crit Care Med 2000;162(1):328330.

56. Brown RB, Kruse JA, Counts GW, Russell JA, Christou NV, Sands ML. Double-blind study of endotracheal tobramycin in the treatment of gram-negative bacterial pneumonia. The Endotracheal Tobramycin Study Group. Antimicrob Agents Chemother 1990;34(2):269272.

57. Klick JM, du Moulin GC, Hedley-Whyte J, Teres D, Bushnell LS, Feingold DS. Prevention of Gram-negative bacillary pneumonia using polymyxin aerosol as prophylaxis. II. Effect on the incidence of pneumonia in seriously ill patients. J Clin Invest 1975;55(3):514519 .

58. Ioannidou E, Siempos II, Falagas ME. Administration of antimicrobials via the respiratory tract for the treatment of patients with nosocomial pneumonia: a meta-analysis. J Antimicrob Chemother 2007; 60(6):1216-1226.

59. Mandell LA, Wunderink RG, Anzueto A, Bartlett JG, Campbell GD, Dean NC, et al. Infectious Diseases Society of America/American Thoracic Society consensus guidelines on the management of community-acquired pneumonia in adults. Clin Infect Dis 2007;44(Suppl 2):S27-S72.

60. Arnold HM, Sawyer AM, Kollef MH. Use of adjunctive aerosolized antimicrobial therapy in the treatment of Pseudomonas aeruginosa and Acinetobacter baumannii ventilator-associated pneumonia. Respir Care 2012;57(8):1226-1233.

61. Dhariwal AK, Tullu MS. Colistin: re-emergence of the 'forgotten' antimicrobial agent. J Postgrad Med 2013;59(3):208-215.

62. Lu Q, Yang J, Liu Z, Gutierrez C, Aymard G, Rouby JJ, Nebulized Antibiotics Study Group. Nebulized ceftazidime and amikacin in ventilator-associated pneumonia caused by Pseudomonas aeruginosa. Am J Respir Crit Care Med 2011;184(1):106-115.

63. Palmer LB, Smaldone GC, Chen JJ, Baram D, Duan T, Monteforte $\mathrm{M}$, et al. Aerosolized antibiotics and ventilator-associated tracheobronchitis in the intensive care unit. Crit Care Med 2008;36(7):2008-2013.

64. Wood GC. Aerosolized antibiotics for treating hospital-acquired and ventilator-associated pneumonia. Expert Rev Anti Infect Ther 2011; 9(11):993-1000.

65. Alothman GA, Alsaadi MM, Ho BL, Ho SL, Dupuis A, Corey M, Coates AL. Evaluation of bronchial constriction in children with cystic fibrosis after inhaling two different preparations of tobramycin. Chest 2002;122(3):930-934.

66. Nikolaizik WH, Trociewicz K, Ratjen F. Bronchial reactions to the inhalation of high-dose tobramycin in cystic fibrosis. Eur Respir J 2002;20(1):122-126.

67. Ramsey BW, Pepe MS, Quan JM, Otto KL, Montgomery AB, Williams-Warren $\mathrm{J}$, et al. Intermittent administration of inhaled tobramycin in patients with cystic fibrosis. Cystic Fibrosis Inhaled Tobramycin Study Group. N Engl J Med 1999;340(1):23-30. 
68. Cheer SM, Waugh J, Noble S. Inhaled tobramycin (TOBI): a review of its use in the management of Pseudomonas aeruginosa infections in patients with cystic fibrosis. Drugs 2003;63(22): 2501-2520.

69. Edson RS, Brey RH, McDonald TJ, Terrell CL, McCarthy JT, Thibert JM. Vestibular toxicity due to inhaled tobramycin in a patient with renal insufficiency. Mayo Clin Proc 2004;79(9):11851191.
70. Rubin BK. Aerosolized antibiotics for non-cystic fibrosis bronchiectasis. J Aerosol Med Pulm Drug Deliv 2008;21(1):71-76.

71. Prober CG, Walson PD, Jones J. Technical report: precautions regarding the use of aerosolized antibiotics. Committee on Infectious Diseases and Committee on Drugs. Pediatrics 2000;106(6):E89.

72. Palmer LB, Smaldone GC. Reduction of bacterial resistance with inhaled antibiotics in the intensive care unit. Am J Respir Crit Care Med 2014;189(10):1225-1233.

\section{Discussion}

Rubin: Great presentation. I want to throw you a curveball. We're respiratory therapists here, and we think about treating infections in the lungyou focused on CF and non-CF bronchiectasis and ventilator-associated infections - and yet the airways also include the nose and paranasal sinuses. Did you have any comments or observations related to treatment of the nose or sinuses? After you've commented, I'll also turn that over to Beth [Laube], who's studied this.

Restrepo: No, I didn't really review upper airway infections, and it's a very interesting point. I really don't have too much knowledge in that area. I think, based on what I know about anesthetics and antibiotics, that they're very effective and have good results in pharyngitis and sinusitis. Most of these infections are viral. I'm hoping that by improving the delivery devices for antibiotic inhalation, efficacy will be increased. The use of inhalation therapies may increase just because, particularly in the pediatric world, everyone who comes with a fever may receive antibiotics. I think the overuse of antibiotics is what's driving the resistance. I'm not so sure what the impact would be, but it's an interesting question.

Rubin: Beth, would you mind commenting on this? I know it's been an area of your research.

Laube: I think that intranasal delivery of aerosols is a new frontier for a lot of investigators. We've focused a good deal on delivery to the lungs for a long time, but the nasal cavity is equally important in terms of delivering aerosols. There are many issues, but the wrong particle size and delivery system can lead to poor deposition in the nasal cavity, just like in the lung. Certainly, if we're trying to deposit in the sinuses and target any kind of infection in the sinuses, that's probably the most difficult target in the nasal cavity. However, targeting the sinuses with aerosolized antibiotics would probably be very beneficial over time. I think there are many investigators looking at this now, but one of the problems is that the orifices to the sinuses are so small that very few particles reach the sinuses with traditional nebulizers or dry powder or propellant-driven aerosols. So there is the need for new devices and new ways of thinking to improve delivery of aerosolized drugs to the nasal cavity and the sinuses.

Willson: I was interested to hear you talk about prophylaxis and VAP or ventilator-associated infection. It concerns me quite a bit because I think that it's the routine that once there's an endotracheal tube, the airway becomes colonized because there is a biofilm on that tube that's not going to be penetrated by antibiotics. My guess and my concern is-and you referred to overuse of antibiotics- that this is a whole area where antibiotics are overused, and we really don't understand the pathogenesis very well. If you would just comment on that?

Restrepo: I am with you; I don't think we should be using antibiotics to prevent these conditions. In addition, you mentioned the word biofilm, which I think is a key aspect of what is a device-related condition. From the practical point, I don't think it should be recommended. I believe the diagnosis of tracheobronchitis that started emerged because after the change in policy, nobody can say the word VAP because you may not get paid. I don't have anything against the diagnosis of tracheobronchitis, and this European group has done a very good job, but these data are based on x-rays. So how good are the $\mathrm{x}$-rays in patients who are critically ill and on mechanical ventilation compared with computed tomography (CT) scan? How can we differentiate between tracheobronchitis and VAP? I am a big proponent of shorter-duration antibiotics and definitely doing inhalational therapy will increase antibiotic use. These newer data from Lucy Palmer ${ }^{1}$ are getting a lot of publicity, and I'm scared how this could be interpreted from a very small number of subjects exposed to inhaled antibiotic.

* MacIntyre: Can I pursue that a little bit more? It always seems to me that it makes more sense to treat tracheobronchitis rather than pneumonia with an aerosol because aerosols are better deposited in the airways. So let me just create a scenario. A patient is doing better and resolving whatever the disease was, but purulent sputum has developed, and suctioning frequency has gone up. A Gram stain shows Gram-negative bugs. There is plus/minus fever and plus/minus elevated white blood cell count. Chest x-ray hasn't changed; gas exchange hasn't really changed. All of this is limiting our ability to get them off the vent because guidelines say if you're 
suctioning people more than once every hour or two, they probably still need an endotracheal tube. Is that a scenario where any of you might consider an aerosolized antibiotic? It would meet my vague definition of tracheobronchitis, and it seems to be limiting my ability to get this patient off the ventilator because of all these purulent secretions. Not a pneumonia; but would you treat with an aerosolized antibiotic? I'm not sure I know the answer.

Restrepo: That's a great question. I am also in the ICU, and I have the same patients you do. I think there are two important points. One point is, yes, by giving inhaled antibiotics, we might be able to suppress the bacteria and decrease the inflammation, and we might be able to notice a decrease in sputum and achieve weaning. But, at the same time, I wonder how much of the aerosolized antibiotics can get into the biofilm. I think that's the bottom line. Because the bacteria will remain in the biofilm inside the tube, where complete eradication will not happen unless you are able to remove the tracheostomy or endotracheal tube. I think the future is devices that can remove the biofilm from inside of the tube or the use of new silver-coated tubes or tubes coated with other materials that will prevent biofilm formation from occurring.

* MacIntyre: I agree with you, but my approach to treating biofilms is to get the tube out. And so what I'm really focusing on is treating the tracheobronchitis that's creating the sputum that's creating the delay in getting the tube out.

Restrepo: I do not treat tracheobronchitis in my practice. I wait for the tracheobronchitis to show me that it's pneumonia, and then I will treat the pneumonia because if I start chasing everyone in my ICU who has tracheobronchitis, I will end up using a lot of antibiotics, and that is not what
I want to do. Now, will there be a place for aerosolized antibiotics versus systemic antibiotics addressing your specific question? The answer is that I don't know. Some of these data suggest that you may; according to small trials, ${ }^{2}$ we will be able to achieve what you are looking for, which is clinical cure. We have other clinicians here, so what do you think?

† Fink: Having been involved with some antibiotic development for delivery to ventilated patients, one of the big criteria was the minimum inhibitory concentration-specific antibiotic (the rate at which both the normal and resistant organisms respond). You have to reach a certain level of antibiotic in the lung to reach that minimum inhibitory concentration. The problem with systemic antibiotics is that maybe $2 \%$ of the antibiotics, especially with aminoglycosides, get to the lung, which means you end up with close to toxicity levels in the blood, and you can't reach the minimum inhibitory concentration in the lung, which is really the basis for antibiotics on the ventilator. Treating tracheobronchitis is impressive, but the level of evidence isn't there to support it as an indication for treatment. It appears to make a difference, but the evidence to say it's really worth treating isn't there (which is $90 \%$ of our practice, I think). The focal deposition of antibiotics with the worst disease with pneumonia is probably the point at which most of the aerosol collects, and if you can get minimum inhibitory concentration to that level and maybe get some resolution, it speaks to the value of doing serial dosing rather than one dose that goes everywhere. Hopefully, we'll get more data to show that if we can have an area of focal deposition and then after treatment for a day those foci change, subsequent doses will get us deeper down the lungs. But with the endotracheal tube, you probably don't get bigger than $2-3-\mu \mathrm{m}$ particles coming out anyway. The data about $1 \mu \mathrm{m}$ being exhaled is probably somewhat dated because we now know that it goes from 40 to $30 \%$, and then all your nanoparticles go to about $80 \%$. Having $1-\mu \mathrm{m}$ particles can get you fairly good deposition; it's just that the volume of drug is really low compared with a 3- or 5- $\mu \mathrm{m}$ particle.

Hill: Great talk, Marcos. My question has to do with the use of combinations of inhaled and systemic antibiotics, which is done probably most of the time when inhaled antibiotics are used. What's the evidence that there might be some potentiation of effect, or are they just overlapping and not adding much?

Restrepo: As I mentioned before, the meta-analysis ${ }^{2}$ suggested that the combination is better than aerosolized antibiotics alone. In practice, by the time you start using aerosolized antibiotics, you are so desperate that you may have only one antibiotic left due to antimicrobial resistance. So you're not going to get rid of the systemic antibiotics, but your final clinical outcome may no longer be achieving clinical success. Therefore, I think the reality is that, in common practice, we cannot use aerosolized antibiotics alone to treat the whole spectrum of disease. I believe, and it's supported by these data, that two drugs are ideal. But the cohorts that are included in that study that received aerosolized antibiotics got it late and in addition to systemic antibiotics. Therefore, it will be difficult to see if we are going to be able to prove that the theory is good. This is why I think Lucy Palmer's study $^{1}$ is interesting because it uses the same antibiotics we use in clinical practice in addition to aerosolized antibiotics. This is the first one to show that it's probably not achieving synergistic effects, but it's just achieving more accumulation of the medication in the affected area where the systemic antibiotics haven't been able to completely clear and suppress the infection. 
Hill: I can imagine that it depends on the scenario; I think in the ICU where you have systemic infections, you need systemic therapy. In out-patients, it may be that the suppression you get with inhaled antibiotics as a solo therapy may have some value. Also, it might have to do with the antibiotic. For example, gentamicin doesn't penetrate the lung very well, and you can imagine that combining systemic with inhaled gentamicin would be effective. With other antibiotics that have good lung penetration, maybe not so much.

Restrepo: We were talking so much about VAP that I answered only for VAP. I completely agree; this is the reason why most of the RCTs on CF and non-CF bronchiectasis don't use systemic antibiotics because they can achieve good results just with the aerosolized antibiotics. Remember that there is no resistance when the pathogens die. One of the big questions is whether you achieve complete eradication of the pathogen to the point it will not grow back. That's the part that we have not really been able to answer because we have focused mainly on all these RCTs driven by industry. The industry may have only one product, and they compare that product against placebo. By the FDA rules, you couldn't have another antibiotic at the same time as aerosolized antibiotics because otherwise they will not believe your data. So we have the constriction where those kinds of studies are not there just because it's part of the exclusion criteria. It's a problematic part of aerosolized antibiotics. How much of the effect could be achieved from $100 \%$ on only one antibiotic? It's a complex issue. I don't know, but systemic antibiotics are not the answer for all these chronic condi- tions like $\mathrm{CF}$ and non-CF bronchiectasis.

Berlinski: Thank you for the nice presentation. One of the problems that I think that we have as practicing pulmonologists is that new inhaled antibiotics are being approved using the model approved 20 years ago for one drug (namely, TOBI). However, when there was no other drug, it was easy. The problem now is there are two different antibiotics that are approved to do the same thing. How do you get the third-party payers to pay for that therapy? I think we can have the greatest device, we can have the greatest drugs, but if we don't have data that support $\mathrm{A}$ is better than $\mathrm{B}$ or worse than $\mathrm{C}$, then those devices or therapies will not be paid for, and patients will not have access. I understand from talking to those who develop the antibiotics that we want our drug to be approved. We need comparative data, and I think that something needs to happen at the regulatory level, and the requirement should probably be different. Also, we need some discussion about the ethics of using placebos in therapies that are already proven to work for those patients.

Restrepo: I agree with you. I think this is an issue, and I think this is what the World Health Organization is trying to tell us. We're running out of solutions, and we need to invest, but the industry needs to invest also. What I believe is happening that, in comparison with CF research, which is very well structured and very well done, the non-CF bronchiectasis world is now moved by the industry, which happens to be interested because aerosolized antibiotics have the potential to be given for a long time. So if you're going to get something for a long time, maybe there is money in it for the industry. The industry is less interested in investing for something such as antibiotics that will be used for 14 days, where it is less likely that I'm going to make money. This is why Nick Hill is making a life with pulmonary hypertension-there are more medications than patients! The point is that this larger cohort is going to help us get more organized, and I think that the future of inhaled medication in terms of antibiotics is exciting thanks to all these other conditions that go beyond VAP. I think VAP is a very restricted topic, and now we're going a little bit farther. I believe that industry cannot drive the science by themselves: there is a need for investments from organizations and from the National Institutes of Health (NIH) and other institutions to recognize that this is an area that requires further exploration.

* Neil R MacIntyre MD FAARC, Division of Pulmonary and Critical Care Medicine, Duke University, Durham, North Carolina, representing InspiRx.

$\dagger$ James B Fink PhD RRT FAARC, James B Fink LLC, San Mateo, California, and Division of Respiratory Therapy, Georgia State University, Atlanta, Georgia, representing Aerogen.

\section{REFERENCES}

1. Palmer LB, Smaldone GC. Reduction of bacterial resistance with inhaled antibiotics in the intensive care unit. Am J Respir Crit Care Med. 2014; 189(10):1225-1233.

2. Ioannidou E, Siempos II, Falagas ME. Administration of antimicrobials via the respiratory tract for the treatment of patients with nosocomial pneumonia: a meta-analysis. J Antimicrob Chemother. 2007;60(6):1216-1226.

This article is approved for Continuing Respiratory Care Education credit. For information and to obtain your CRCE

(free to AARC members) visit

www.rcjournal.com 